\title{
Topical application of ALA and ALA hexyl ester on a subcutaneous murine mammary adenocarcinoma: tissue distribution
}

\author{
C Perotti', A Casas', H Fukuda', P Sacca' and A Batlle*,' \\ 'Centro de Investigaciones sobre Porfirinas y Porfirias (CIPYP), CONICET and Department of Biochemistry, Facultad de Ciencias Exactas y Naturales, \\ University of Buenos Aires, Argentina
}

\begin{abstract}
Although 5-aminolevulinic acid (ALA)-based photodynamic therapy (PDT) has proven to be clinically beneficial for the treatment of certain cancers, including a variety of skin cancers, optimal tissue localisation still remains a problem. An approach to improve the bioavailability of protoporphyrin IX (PpIX) is the use of ALA derivatives instead of ALA. In this work, we employed a subcutaneous murine mammary adenocarcinoma to study the tissue distribution pattern of the ALA hexyl ester (He-ALA) in comparison with ALA after their topical application in different vehicles. He-ALA induced porphyrin synthesis in the skin overlying the tumour (SOT), but it did not reach the tumour tissue as efficiently. Only $5 \mathrm{~h}$ after He-ALA lotion application, tumour porphyrin levels surpassed control values. He-ALA delivered in cream induced a substantially lower porphyrin synthesis in SOT, reinforcing the importance of the vehicle in the use of topical PDT. Porphyrin levels in internal organs remained almost within control values when He-ALA was employed. The addition of DMSO to ALA formulation slightly increased tumour and SOT porphyrin biosynthesis, but it did not when added to He-ALA lotion.

British Journal of Cancer (2003) 88, 432 -437. doi:10.1038/sj.bjc.6600665 www.bjcancer.com
\end{abstract}

(c) 2003 Cancer Research UK

Keywords: photodynamic therapy (PDT); aminolevulinic acid (ALA); ALA derivatives (ALA hexyl ester)

Photodynamic therapy (PDT) of cancer is based on the administration of a photosensitising compound with tumour-localising properties, and subsequent irradiation with light of an appropriate wavelength leading to selective damage to the treated tissue (Henderson and Dougherty, 1992). The administration of 5aminolevulinic acid (ALA) to cells and tissues results in the production of protoporphyrin IX (PpIX), through the haem biosynthetic pathway, which can be clinically used as a photosensitiser for both photodetection and also as a good alternative of cancer PDT (Kennedy et al, 1990, 1996; Peng et al, 1997).

Although ALA-based PDT has proven to be clinically beneficial for the treatment of certain cancers including a variety of skin cancers, optimal tissue localisation is still a problem to be solved. As ALA is a small molecule, it can penetrate through the skin and into tumours after topical application. However, the clinical use of PDT with ALA-induced PpIX is limited by different factors, such as ALA diffusion through biological barriers, localisation of PpIX, availability of oxygen and rapid photobleaching of PpIX (Van der Akker et al, 2000a).

Since the skin and very likely the stratum corneum are the main biological barriers limiting ALA diffusion, high ALA doses have to be applied to produce sufficient PpIX levels suitable for PDT (Cairnduff et al, 1994; Peng et al, 1995).

*Correspondence: Prof. Dr A Batlle; Viamonte I88I I0A, I056 Buenos Aires, Argentina; E-mail: batlle@mail.retina.ar

Received 10 December 2001; revised 19 July 2002; accepted 27 September 2002
An approach to improve the bioavailability of PpIX is the use of ALA derivatives instead of ALA as precursors for PpIX synthesis. ALA esters, which are more lipophilic than ALA itself, are expected to enhance its uptake, penetration and distribution. Several ALA esters have been synthesised and tested in vitro in different cell lines and it has been found that long-chained ALA esters were more efficient than short-chained ones at improving PpIX production in cells (Kloek and Beijersbergen van Henegouwen, 1996; Gaullier et al, 1997; Casas et al, 2001a).

5-Aminolevulinic acid hexyl ester (He-ALA) has proven to be successful in inducing PpIX production and distribution in human and porcine bladder mucosa ex vivo (Marti et al, 1999) and in patients (Lange et al, 1999).

On the other hand, topical use of ALA esters was not found to be better than ALA at increasing PpIX production, yet a surprisingly high photosensitiser selectivity was achieved (Peng et al, 1996; Casas et al, 2001b; Moan et al, 2001).

Another approach to optimise ALA penetration is the use of enhancers. The results of experiments with penetration enhancers and tape stripping indicate that the stratum corneum acts as a barrier against ALA and He-ALA. The use of enhancers like azacycloalkane derivatives augments PpIX production, especially in the case of He-ALA (Van der Akker et al, 2000a).

Dimethylsulphoxide (DMSO), which also acts as a penetration enhancer, among other amphiphilic molecules penetrates skin well, probably because the electron-rich part of the molecule has affinity for the aqueous layers of the stratum corneum while the electron-poor portion prefers the lipid region (Wiechers, 1989). 
It has been shown that DMSO can increase the penetration of various chemical agents through human skin (Stoughton and Fritdch, 1964), although the mechanism is not yet known. It has been reported that DMSO can improve the accumulation of PpIX in cell lines (Malik et al, 1995). Employing ALA plus DMSO in vivo in a transplantable murine adenocarcinoma, Casas et al (2000) have found a higher porphyrin accumulation in the skin overlying the tumour tissue and in the first $2 \mathrm{~mm}$ of tumour.

The aim of this work was to improve the clinical application of ALA PDT by studying the tissue distribution pattern of He-ALA compared to ALA after their topical application in two different vehicles in a subcutaneous murine mammary adenocarcinoma implanted in mice. The effect of adding DMSO to the formulations of both compounds was also evaluated.

\section{MATERIALS AND METHODS}

\section{Animals}

Male BALB/c mice 12 weeks old, weighing 20-25g, were used. They were provided with food (Purina 3, Molinos Río de la Plata) and water ad libitum. A suspension of $1.65 \times 10^{5}$ cells of the LM2 cell line (Galli et al, 2000) derived from the murine mammary adenocarcinoma M2 (Instituto Roffo, Buenos Aires) was subcutaneously injected on the flanks of male $B A L B / c$ mice. Experiments were performed at approximately day 20 after implantation. Tumours of the same uniform size were employed ( $1 \mathrm{~cm}$ diameter). Animals received human care and were treated in accordance with guidelines established by the Animal Care and Use Committee of the Argentine Association of Specialists in Laboratory Animals (AADEALC), in full accord with the UK Guidelines for the Welfare of Animals in Experimental Neoplasia (Workman et al, 1998).

\section{Drugs}

ALA was purchased from Sigma Chemical Co., St Louis, MO, USA. ALA hexyl ester (He-ALA) was synthesised according to the method previously described in Casas et al (1999a). All other chemicals were of analytical grade.

\section{ALA administration}

The hydrochloric acid $(\mathrm{HCl})$ salt of ALA and He-ALA were dissolved in saline in a final volume of $0.2 \mathrm{ml}$ immediately before use (lotion). The addition of $5 \%$ DMSO to this saline lotion constituted the lotion/DMSO formulation. For the cream preparations, ALA and He-ALA were freshly dissolved in $50 \mathrm{mg}$ of an oil in water emulsion cream (Genargen, Argentina).

Both ALA formulations were applied on the tumour, having shaved the hair and rubbing with a smooth paintbrush for a period of $5 \mathrm{~min}$, time at which no vestiges of either cream or lotion were visible. Before any application, mice received mild anaesthesia (Fentanyl and Diazepam). All formulations were applied under occlusive dressing to avoid distribution of the compounds.

\section{Tissue porphyrin extraction}

After ALA or He-ALA topical application, animals were killed. Before killing mice were injected with heparin $(0.15 \mathrm{ml}, 1000 \mathrm{UI})$, and after killing they were perfused with $200 \mathrm{ml}$ of sterile saline. The tissue samples were homogenised in a $4: 1$ solution of ethyl acetate:glacial acetic acid mixture according to Batlle (1997). Briefly, the mixtures were centrifuged for $30 \mathrm{~min}$ at $3000 \mathrm{~g}$, and the supernatants were added with an equal volume of $5 \% \mathrm{HCl}$. Extraction with $\mathrm{HCl}$ was repeated until there was no detectable fluorescence in the organic layer. The aqueous fraction was used for the determination of porphyrins. For fluorometric determina- tion, a Shimadzu RF-510 spectrofluorometer was used, with an emission wavelength of $604 \mathrm{~nm}$ and an excitation wavelength of $406 \mathrm{~nm}$, employing PpIX reference standard.

\section{Statistical analysis}

The unpaired $t$-test was used to establish the significance of differences between groups. Differences were considered to be statistically significant when $P<0.05$. Three mice per group were employed.

\section{RESULTS}

\section{Dose course of porphyrin levels after topical application of ALA or He-ALA}

The dose course of porphyrin levels in tumour, skin and peritumoural skin is shown in Figure $1 \mathrm{~A}-\mathrm{C}$. In tumour, after application of ALA cream or lotion, porphyrin accumulation increased with the amount of ALA applied, reaching a plateau at 5 and $15 \mathrm{mg}$ ALA, respectively. Highest porphyrin levels were found when using ALA lotion with a peak of $1.75 \pm 0.45 \mu \mathrm{g}_{\text {porphyrin }} \mathrm{g}^{-1}$ tissue at $15 \mathrm{mg}$ ALA. In general, employing the ALA lotion, values 3 times higher than either ALA cream or He-ALA were obtained. When using He-ALA cream or lotion, porphyrin levels do not increase significantly over control values.

The addition of $10 \%$ DMSO to ALA lotion increases the amount of porphyrins formed in tumour from $15 \mathrm{mg}$ ALA onwards, although values were not significantly much higher. When employing $20 \mathrm{mg}$ ALA lotion or ALA lotion plus DMSO, $1.75 \pm 0.25$ and $2.5 \pm 0.5 \mu \mathrm{g}$ porphyrin $\mathrm{g}^{-1}$ tumour, respectively, were accumulated. Instead, addition of DMSO to He-ALA lotion did not enhance the amount of synthesised porphyrins.

In normal skin, ALA lotion also induced the synthesis of the highest levels of porphyrin, reaching a plateau of $0.83 \pm 0.13 \mu \mathrm{g} \mathrm{g}^{-1}$ at $10 \mathrm{mg}$ ALA. Addition of DMSO to ALA lotion equalled lotionalone values within the $10-15 \mathrm{mg}$ ALA range, without increasing further porphyrin levels. Again, porphyrins induced by He-ALA in either lotion or cream were within control values.

In the skin overlying the tumour (SOT), plateaus were rapidly reached within the 5-7.5 mg range for both ALA and He-ALA, and porphyrin values were alike for both compounds, independent of the vehicle. ALA cream concentration higher than $15 \mathrm{mg}$ induced significantly lower porphyrin levels compared to those reached at the plateau $(0.29 \pm 0.04, P<0.05)$. Addition of DMSO to ALA lotion showed a sharp peak at $15 \mathrm{mg}$ ALA $\left(1.8 \pm 0.4 \mu \mathrm{g}\right.$ porphyrins $\mathrm{g}^{-1}$ tissue), but no further increase at other points as compared to ALA lotion alone. Addition of DMSO to He-ALA lotion did not enhance porphyrin synthesis but reduced it.

Figure 1D-F depicts porphyrin accumulation in liver, kidney and spleen. In liver tissue, sharp peaks were obtained with $10 \mathrm{mg}$ ALA in cream and lotion plus DMSO $(6.2 \pm 0.85$ and $4.1 \pm 0.25 \mu \mathrm{g}$ porphyrins $\mathrm{g}^{-1}$ tissue, respectively). Slight increases of porphyrin levels were found after topical application of He-ALA and ALA lotion, although they were not significantly different from the control.

In kidney, maximum porphyrin accumulation was reached with $15 \mathrm{mg}$ ALA cream $\left(3.2 \pm 0.3 \mu \mathrm{g}\right.$ porphyrins $\mathrm{g}^{-1}$ tissue). After application of ALA lotion alone or plus DMSO, values doubled controls. After He-ALA treatment porphyrins did not increase significantly over the control in the range of doses studied, independent of the vehicle.

In spleen, the highest levels of porphyrins were accumulated after applying $10 \mathrm{mg}$ ALA cream and $15 \mathrm{mg}$ ALA lotion $(3.2 \pm 0.5$ and $3.9 \pm 0.5 \mu \mathrm{g}$ porphyrin $\mathrm{g}^{-1}$ tissue, respectively). Again, porphyrins were slightly increased over the control after He-ALA treatment without significant changes in the range of doses 

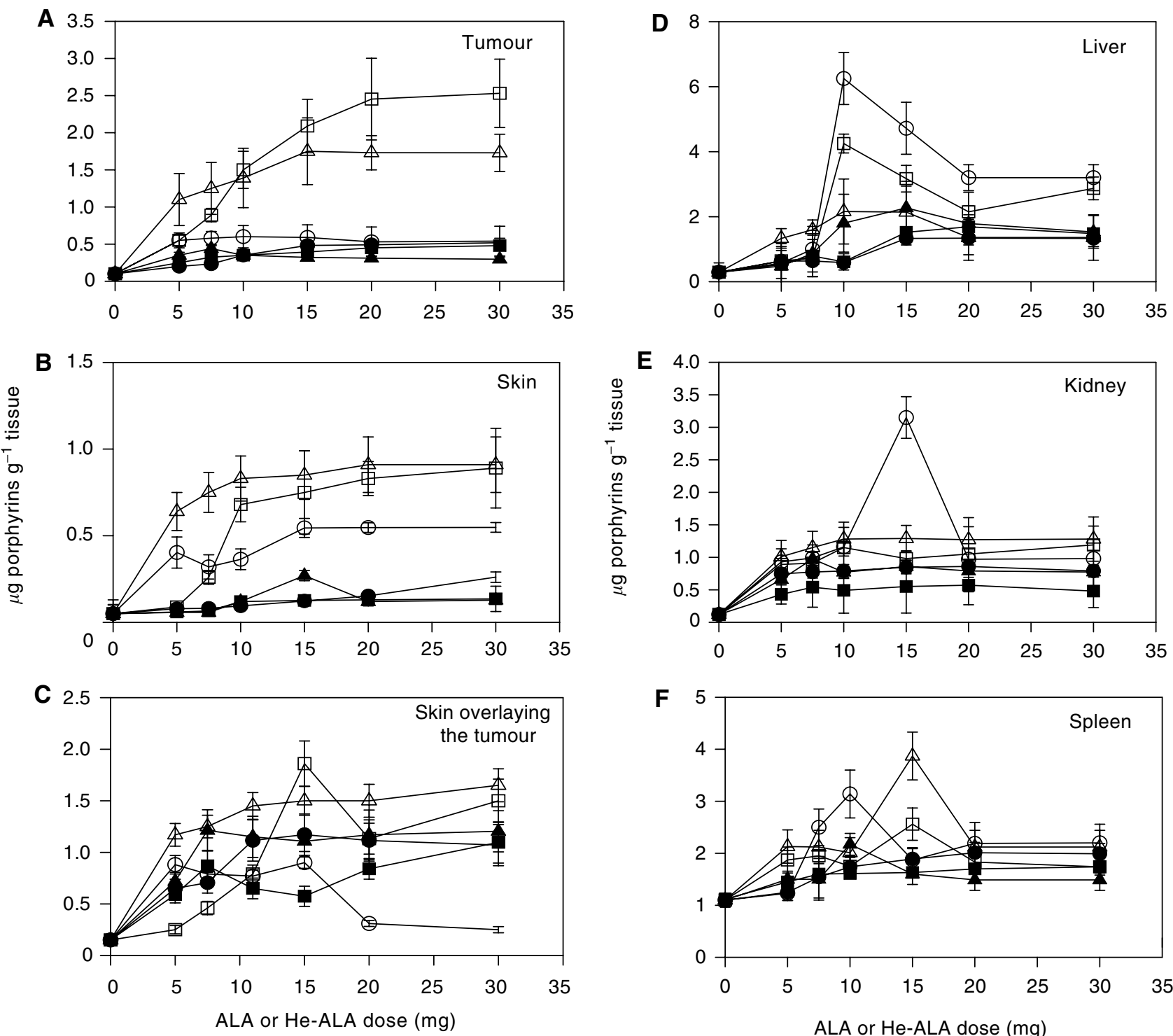

Figure I Porphyrin accumulation after topical application on the tumour and skin of various quantities of ALA or He-ALA. Different amounts of ALA cream $(\bigcirc)$, ALA lotion $(\triangle)$, ALA lotion/DMSO $(\square)$, He-ALA cream $(\mathbf{O})$, He-ALA lotion $(\mathbf{\Lambda})$ and He-ALA lotion/DMSO $(\square)$ were applied on the tumour. After $3 \mathrm{~h}$, tumour $(\mathbf{A})$, skin $(\mathbf{B})$, skin overlying the tumour $(\mathbf{C})$, liver $(\mathbf{D})$, kidney $(\mathbf{E})$ and spleen $(\mathbf{F})$ were excised and porphyrins were extracted as detailed in the Materials and Methods. Each data point represents the average of three determinations. Error bars show standard deviations.

studied. Addition of DMSO to ALA did not enhance porphyrin formation.

\section{Tissue distribution of porphyrins after ALA or He-ALA topical application}

The pattern of porphyrin accumulation in lung, heart, ear, gut, bladder and brain after application of different amounts of ALA in cream or lotion is shown in Tables 1 and 2, respectively. When using both ALA formulations, heart and gut showed a marked increase in porphyrin levels. In addition to these tissues, some enhanced porphyrin accumulation in a dose-dependent way after ALA lotion application was found in ear and bladder. He-ALA cream increases basal porphyrin levels in a dose-dependent way in the heart (control $0.29 \pm 0.03$ vs $30 \mathrm{mg}$ He-ALA $0.57 \pm 0.05 \mu \mathrm{g}$ porphyrin $\mathrm{g}^{-1}$ tissue, $P<0.05$ ) and bladder (control $0.36 \pm 0.03$ vs $30 \mathrm{mg}$ He-ALA $0.83 \pm 0.08 \mu \mathrm{g}$ porphyrin $\mathrm{g}^{-1}$ tissue, $P<0.05$ ), while the other tissues remain within control values. On the other hand,
He-ALA lotion did not induce any change in basal porphyrin levels for all the tissues studied (data not shown).

\section{Time course of porphyrin levels after ALA or He-ALA topical application}

The time course of porphyrin levels after topical application of ALA or He-ALA cream and lotion on tumour, skin and SOT is shown in Figure 2A-C. Maximal accumulation was found in tumour $3 \mathrm{~h}$ after ALA application. He-ALA lotion induced an increase slightly above control at $5 \mathrm{~h}$ (very significant), but HeALA cream did not produce porphyrin synthesis.

In normal skin, ALA in both preparations induced a peak of porphyrins at $8 \mathrm{~h}$. When using He-ALA in lotion, a defined peak was observed at $5 \mathrm{~h}$ but none in its cream formulation.

SOT exhibits a peak $3 \mathrm{~h}$ after application of ALA lotion, whereas ALA cream and both He-ALA formulations induced peaks at $8 \mathrm{~h}$. In this tissue, levels obtained with He-ALA lotion were high and equalled those obtained with ALA lotion. 
Table I Tissue distribution of porphyrins after application of different amounts of ALA cream

\begin{tabular}{|c|c|c|c|c|c|c|}
\hline $\begin{array}{l}\text { Control } \\
7.5 \mathrm{mg} \text { ALA } \\
\text { I5 mg ALA } \\
20 \mathrm{mg} \text { ALA } \\
30 \mathrm{mg} \text { ALA }\end{array}$ & $\begin{array}{l}0.49 \pm 0.08 \\
0.53 \pm 0.07 \\
0.60 \pm 0.09 \\
0.43 \pm 0.06 \\
0.50 \pm 0.07\end{array}$ & $\begin{array}{l}0.29 \pm 0.03 \\
0.65 \pm 0.06 \\
1.89 \pm 0.21 \\
2.53 \pm 0.15 \\
2.83 \pm 0.41\end{array}$ & $\begin{array}{l}0.15 \pm 0.05 \\
0.20 \pm 0.03 \\
0.21 \pm 0.05 \\
0.11 \pm 0.05 \\
0.20 \pm 0.05\end{array}$ & $\begin{array}{l}0.37 \pm 0.07 \\
1.53 \pm 0.23 \\
1.79 \pm 0.23 \\
1.83 \pm 0.26 \\
2.15 \pm 0.31\end{array}$ & $\begin{array}{l}0.36 \pm 0.03 \\
0.51 \pm 0.07 \\
0.63 \pm 0.03 \\
0.58 \pm 0.07 \\
0.40 \pm 0.06\end{array}$ & $\begin{array}{l}0.11 \pm 0.01 \\
0.11 \pm 0.05 \\
0.13 \pm 0.01 \\
0.18 \pm 0.02 \\
0.17 \pm 0.02\end{array}$ \\
\hline
\end{tabular}

Different amounts of ala cream were topically applied on the tumour. Mice were killed $3 \mathrm{~h}$ after drug administration and porphyrins $\left(\mu \mathrm{gg}^{-1}\right.$ tissue) were determined spectrophotometrically.

Table 2 Tissue distribution of porphyrins after application of different amounts of ALA in lotion

\begin{tabular}{|c|c|c|c|c|c|c|}
\hline & Lung & Heart & Ear & Gut & Bladder & Brain \\
\hline $\begin{array}{l}\text { Control } \\
7.5 \mathrm{mg} \text { ALA } \\
\text { I5 mg ALA } \\
20 \mathrm{mg} \text { ALA } \\
30 \mathrm{mg} \text { ALA }\end{array}$ & $\begin{array}{l}0.49 \pm 0.08 \\
0.28 \pm 0.05 \\
0.39 \pm 0.05 \\
0.45 \pm 0.03 \\
0.52 \pm 0.04\end{array}$ & $\begin{array}{l}0.29 \pm 0.03 \\
1.43 \pm 0.03 \\
1.53 \pm 0.21 \\
1.91 \pm 0.41 \\
2.13 \pm 0.33\end{array}$ & $\begin{array}{l}0.15 \pm 0.05 \\
0.58 \pm 0.06 \\
0.82 \pm 0.07 \\
1.24 \pm 0.10 \\
1.45 \pm 0.34\end{array}$ & $\begin{array}{l}0.37 \pm 0.07 \\
1.19 \pm 0.03 \\
1.41 \pm 0.12 \\
1.43 \pm 0.11 \\
1.97 \pm 0.25\end{array}$ & $\begin{array}{l}0.36 \pm 0.03 \\
0.40 \pm 0.04 \\
0.53 \pm 0.07 \\
0.93 \pm 0.06 \\
0.88 \pm 0.09\end{array}$ & $\begin{array}{l}0.11 \pm 0.05 \\
0.15 \pm 0.02 \\
0.17 \pm 0.03 \\
0.15 \pm 0.03 \\
0.20 \pm 0.04\end{array}$ \\
\hline
\end{tabular}

Different amounts of ALA in lotion were topically applied on the tumour. Mice were killed $3 \mathrm{~h}$ after drug administration and porphyrins $\left(\mu \mathrm{g} \mathrm{g}^{-1}\right.$ tissue) were determined spectrophotometrically.

In Figure 2D-F, liver, kidney and spleen time courses are depicted. In these three tissues, ALA in either formulation induced different peak times; instead porphyrin accumulation from $\mathrm{He}-$ ALA did not change from basal porphyrin levels in any tissue.

\section{DISCUSSION}

The kinetics of ALA in lotion and cream formulations have already been discussed in a previous work (Casas et al, 1999b). Here we will focus on the differences between ALA and He-ALA topically applied, also in lotion and cream vehicles.

From these results, we can conclude that He-ALA induces porphyrin synthesis in the skin overlying the tumour but it cannot reach the tumour tissue as efficiently. Only $5 \mathrm{~h}$ after He-ALA lotion application, tumour porphyrin levels surpass control values. Porphyrins formed from He-ALA were more above controls in remote skin tissue than in tumour tissue. Porphyrin concentration in internal organs remained within control values when He-ALA was employed.

Moreover, even in SOT, although He-ALA lotion-induced synthesis equals ALA lotion, the amount of the ester needed is 1.5 higher than that of ALA. He-ALA delivered in cream induced a substantially lower porphyrin synthesis than in saline, reinforcing the importance of the vehicle in the use of topical PDT.

Moan et al (2001) studied the PpIX formation after topical application of ALA, ALA methyl ester and He-ALA on normal skin and on skin overlying a subcutaneous human colon adenocarcinoma. By means of an in vivo fluorescence signal from SOT measurements, they found that ALA induced the same levels of PpIX as compared to He-ALA applied in a $20 \%$ cream formulation, but in remote skin sites no fluorescence was detected. In our work, we have also found that in SOT porphyrin levels induced by HeALA are equal to those obtained from ALA, and by means of porphyrin extraction we have demonstrated that He-ALA does not induce a significant amount of photosensitiser in the subcutaneous tumour itself.

In accordance with our findings, Van den Akker et al (2000b) demonstrated that the stratum corneum was the main barrier for He-ALA penetration. They found that the ALA ester did not induce higher PpIX production in normal mouse skin as compared to ALA. Employing a cream formulation and tape stripping of the stratum corneum, they demonstrated that this was the layer limiting and lowering PpIX production.

Also Van den Akker et al (2000b), using hairless mice, showed that ALA pentyl ester produces only slightly more PpIX than ALA in UVB-induced (pre)cancerous skin lesions, while in normal skin, porphyrin levels were equal from both ALA compounds. They found higher PpIX levels in the stratum corneum of lesional skin, but not in the dysplastic layer of the epidermis, showing that this ester also poorly diffuses as compared to ALA. These lesions consisted of actinic and seborrhoeic keratosis and squamous cell carcinomas.

However, in a previous work (Casas et al, 2001b) we have analysed porphyrin formation in chemically induced squamous papillomas, after topical application of ALA and He-ALA in cream and lotion formulations. Not only did we find porphyrin synthesis from ALA in these highly keratinised papillomas, but we also found porphyrin accumulation in internal organs, showing that the ALA-hexyl ester does reach the dermis in this tumour model. Moreover, after applying He-ALA in the normal skin of nontumour-bearing mice, we also found the same pattern in internal organs. Even in these hyperkeratotic papillomas, this molecule diffuses freely. We could predict that He-ALA may be highly useful, as it has already been proven with ALA methyl ester (Fritsch et al, 1998) in the treatment of actinic keratosis and verruca vulgaris.

In SOT, He-ALA peaks are delayed as compared to ALA lotion, and this can be explained either by considering the additional step of esterase breakage of the alcohol chain, difficulties in crossing the stratum corneum. The fact that porphyrin biosynthesis induced from ALA cream is also delayed, favours the latter hypothesis. Moreover, culturing different tissue explants (tumour, normal skin, SOT, liver, kidney and spleen) exposed to ALA or He-ALA, we found that porphyrin levels from either compounds were similar, supporting the proposal that there are no differences on esterase activity for any tissue (Perotti et al, 2002).

The attempt to raise tumour porphyrin biosynthesis from $\mathrm{He}$ ALA by adding DMSO failed; on the contrary, the values obtained were even lower. However, Van der Akker et al (2000a) found that penetration enhancers like azacycloalkane derivatives augment PpIX production from He-ALA. These differences may be ascribed to different mechanisms of action for both compounds. Penetration enhancers such as DMSO exert a direct influence on the 

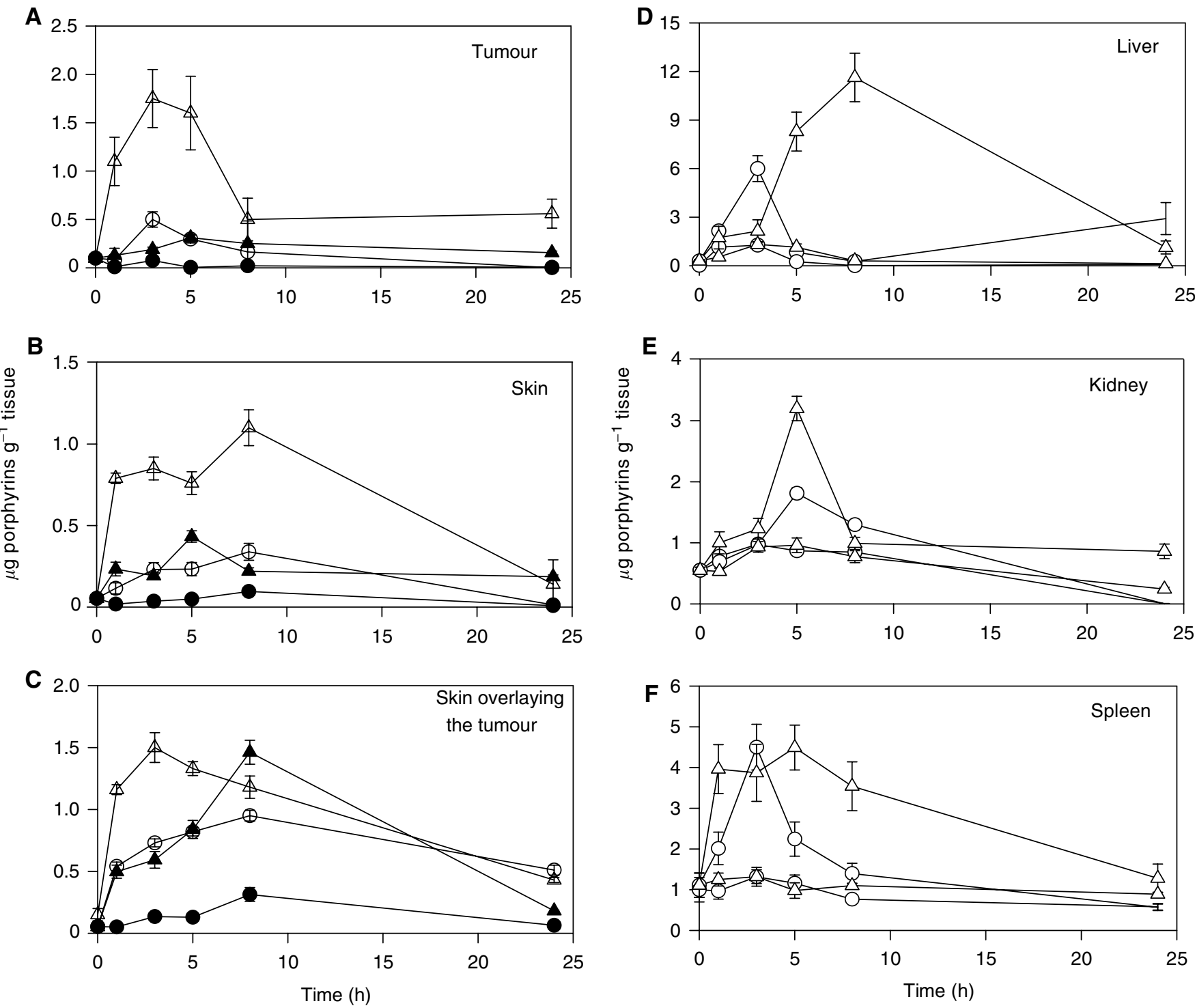

Figure 2 Concentration of ALA and He-ALA-induced porphyrins as a function of time after topical application of ALA and He-ALA in cream or lotion. At

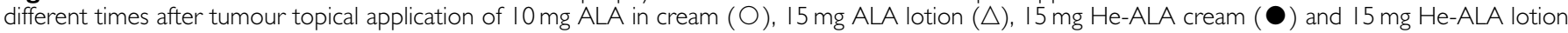
$(\mathbf{A})$, tissues were excised and porphyrins were extracted as detailed in the Materials and Methods section (tumour $(\mathbf{A})$, skin $(\mathbf{B})$, skin overlying tumour $(\mathbf{C})$, liver (D), kidney $(\mathbf{E})$ and spleen $(\mathbf{F})$ ). Each data point represents the average of three determinations. Error bars show standard deviations.

aqueous regions between the polar lipid head groups of the bilayer, altering the solubilising ability of this site, thereby promoting partitioning into the skin. On the other hand, the nonpolar enhancer Azone ${ }^{\mathbb{R}}$ exerts its action on the hydrophobic tails of the bilayer by upsetting their packing and increasing their fluidity (Wiechers, 1989).

In conclusion, according to these results and those from Casas et al (2001b) when compared to ALA, only superficial skin lesions may be successfully treated with topical He-ALA PDT with the advantage of tumour selectivity; instead malignancies such as chest wall progression of breast cancer will probably fail this treatment.

\section{ACKNOWLEDGEMENTS}

This research was supported by grants from the Argentine National Research Council (CONICET) (PIP 4108/96 and 105508/ 98-99) and the Science and Technology Argentine Agency (STAA) (PICT 05-00000-01861). We are very grateful to Mrs Victoria Castillo for her skilful technical assistance. $\mathrm{AM}$ del $\mathrm{CB}$ and HF hold the posts of Superior and Associate Researchers at the CONICET. AC is a postdoctoral CONICET fellow. CP is a 'Carrillo-Oñativia' fellow from the Ministerio de Salud Pública.

\section{REFERENCES}

Batlle A (1997) Porfirias y Porfirinas. Aspectos clínicos, bioquímicos y biología molecular. ED: Acta Bioquímica Clínica Latinoamericana, Buenos Aires Argentina
Cairnduff F, Springer M, Hudson EJ, Ash DV, Brown SB (1994) Superficial photodynamic therapy with topical 5-aminolevulinic acid for superficial primary and secondary skin cancer. Br J Cancer 69: 605-608 
Casas A, Batlle A, Butler A, Robertson D, Brown E, MacRobert A, Riley P (1999a) Comparative effect of ALA derivatives on Protoporphyrin IX production in human and rat skin organ cultures. $\mathrm{Br} J$ Cancer 80: $1525-1532$

Casas A, Fukuda H, Batlle A (1999b) Tissue distribution and kinetics of endogenous porphyrins synthesized after topical application of ALA in different vehicles. Br J Cancer 81: $13-18$.

Casas A, Fukuda H, Di Venosa G, Battle A (2000) The influence of the vehicle on the synthesis of porphyrins after topical application of 5aminolevulinic acid. Implications in cutaneous photodynamic sensitization. Br J Dermatol 143: 1 - 10.

Casas A, Fukuda H, Di Venosa G, Batlle A (2001a) Photosensitisation and mechanism of cytotoxicity induced by the use of ALA derivatives in photodynamic therapy. $\mathrm{Br} J$ Cancer 85: $279-284$

Casas A, Perotti C, Fukuda H, Rogers L, Butler A, Batlle A (2001b) ALA and ALA hexyl ester-induced porphyrin synthesis in chemically induced skin tumours: the role of different vehicles on improving photosensitisation. Br J Cancer 85(11): $1794-1800$

Fritsch C, Homey B, Stahl W, Lehemann P, Ruzicka T, Sies H (1998) Preferential relative porphyrin enrichment in solar keratoses upon topical application of 5-aminolevulinic acid methyl ester. Photochem Photobiol 68: $218-221$

Galli S, Colombo L, Vanzuli S, Daroqui M, Vidal M, Jasnis A, Lustig E, Eiján A. (2000). Characterization of a fibroblastoid mammary carcinoma cell line (LM2) originated from a mouse adenocarcinoma. Int J Oncol 17: $1259-1265$

Gaullier JM, Berg K, Peng Q, Anholt H, Selbo PK, Ma LW, Moan J (1997) Use of 5-aminolevulinic acid esters to improve photodynamic therapy on cells in culture. Cancer Res 57: $1481-1486$

Henderson BW, Dougherty TJ (1992) How does photodynamic therapy work? Photochem Photobiol 55: $145-157$

Kennedy JC, Marcus SL, Pottier RH (1996) Photodynamic therapy and photodiagnosis using endogenous photosensitization induced by 5-aminolevulinic acid: mechanisms and clinical results. J Clin Laser Med Surg 14: 289 - 304

Kennedy JC, Pottier RH, Pross DC (1990) Photodynamic therapy with endogenous protoporphyrin IX: basic principles and basic clinical experience. J Photochem Photobiol B: Biol 6: $143-148$

Kloek J, Beijersbergen van Henegouwen GMJ (1996) Prodrugs of 5-aminolevulinic acid for photodynamic therapy. Photochem Photobiol 64: $994-1000$

Lange N, Jichlinski P, Zellweger M, Forrer M, Marti A, Guillo L, Kucera P, Wagnieres GA, van den Bergh H (1999) Photodetection of early human bladder cancer based on the fluorescence of 5-aminolevulinic acid hexylester induced protoporphyrin IX: a pilot study. Br J Cancer 80: 185 - 193

Malik Z, Kostenich G, Roitman L et al (1995) Topical application of 5-aminolevulinic acid, DMSO and EDTA. Protoporphyrin accumulation in skin and tumours mice. J Photochem Photobiol B Biol 28: $213-218$

Marti A, Lange N, van den Bergh H, Sedmera D, Jichlinski P, Kucera P (1999) Optimisation of the formation and distribution of protoporphyrin IX in the urothelium: an in vitro approach. J Urol 162: 546-552

Moan J, Ma L, Iani V (2001) On the pharmacokinetics of topically applied 5-aminolevulinic acid and two of its esters. Int J Cancer 92: 139 - 143

Peng Q, Berg K, Moan J, Kongshaug M, Nesland JM (1997) 5-Aminolevulinic acid-based photodynamic therapy: principles and experimental research. Photochem Photobiol 65: $235-251$

Peng Q, Moan J, Warloe T, Iani V, Steen H, Bjørseth A, Nesland J (1996) Build-up of esterified aminolevulinic-acid-derivative-induced porphyrin fluorescence in normal mouse skin. J Photochem Photobiol B Biol 34: $95-96$

Peng Q, Warloe T, Moan J, Heyerdahl H, Steen HB, Nesland JM, Giercksky KE (1995) Distribution of 5-aminolevulinic acid-induced porphyrins in nodulo-ulcerative basal cell carcinomas. Photochem Photobiol 62: $906-913$

Perotti C, Casas A, Fukuda H, Sacca P, Batlle A (2002) ALA and ALA hexyl ester induction of porphyrins after systemic administration to tumour bearing mice. $\mathrm{Br} J$ Cancer 87: 790 - 795

Stoughton R, Fritdch W (1964) Influence of dimethylsulfoxide (DMSO) on human percutaneous absorption. Arch Dermatol 90: $512-517$

Van der Akker JT, Bruijn HS, Beijersbergen van Henegouwen GMJ, Star WM, Sterenborg HJCM (2000a) Protoporphyrin IX fluorescence kinetics and localization after topical application of ALA pentyl ester and ALA on hairless mouse skin with UVB-induced early skin cancer. Photochem Photobiol 72: $399-406$

Van der Akker JT, Iani V, Star WM, Sterenborg HJCM, Moan J (2000b) Topical application of 5-aminolevulinic acid hexyl ester and 5-aminolevulinic to normal nude mouse skin: differences in protoporphyrin IX fluorescence kinetics and the role of the stratum corneum. Photochem Photobiol 72: $681-689$

Wiechers J (1989) The barrier function of the skin in relation to percutaneous absorption of drugs. Pharm Weekbl Sci 11: 185-198

Workman P, Balmain A, Hickman JA, Mc Nally NJ, Rohas AM, Mitchison NA, Pierrepoint CG, Laymond R, Stephers TC et al (1998) UKCoordinating Committee on Cancer Research. UKCCCR Guidelines for the Welfare of Animals in Experimental Neoplasia, 2nd ed. Lab Anim 22: $195-201$ 